\title{
A huge mesenteric teratoma in reproductive age woman: a case report
}

\author{
Ruchi Kishore $^{1}$, Pratibha Lambodari ${ }^{2 *}$, Kritika Verma ${ }^{3}$, Anjum Khan ${ }^{4}$, Neelam Singh ${ }^{5}$
}

Department of Obstetrics and Gynaecology, Pt. Jawaharlal Nehru Memorial Medical College, Raipur, Chhattisgarh, India

Received: 29 September 2021

Revised: 02 November 2021

Accepted: 03 November 2021

\section{*Correspondence:}

Dr. Pratibha Lambodari,

E-mail: pratibha.lambodari@gmail.com

Copyright: ( $)$ the author(s), publisher and licensee Medip Academy. This is an open-access article distributed under the terms of the Creative Commons Attribution Non-Commercial License, which permits unrestricted non-commercial use, distribution, and reproduction in any medium, provided the original work is properly cited.

\begin{abstract}
The incidence of dermoid ovarian cyst is $15-20 \%$ of all ovarian neoplasm, which is a common entity. Mesenteric cyst are one of the very rare entities with incidence of 1 in 2,50,000. Dermoid cysts rarely present as mesenteric cysts. Mesenteric dermoid cyst have good prognosis. Here, we report a rare abdominal tumor which was initially diagnosed clinically as an ovarian dermoid cyst but operative and histology revealed it to be mesenteric dermoid cyst. A 36 yearold, multiparous presented with abdominal mass, gradually increasing in size since 1 year with recent onset of abdominal pain. Physical examination revealed abdominal mass of $22 \times 20 \mathrm{~cm}$ size, globular, non-tender, mobile, and cystic to solid in consistency. Contrast-enhanced computed tomography (CECT) showed $23 \times 21 \times 14.4 \mathrm{~cm}$ heterogeneous enhancing mass lesion with areas of fat density and calcifications within, suggestive of neoplastic mass lesion, likely teratoma. Tumor markers were within normal limit. Patient was managed surgically. Laparotomy findings revealed a huge solid mesenteric mass $(22 \times 20 \mathrm{~cm})$ weighing $6.5 \mathrm{kgs}$. Histopathology showed mature cartilage, osteoid formation, fibro-adipose connective tissue, focal lymphoid aggregates, congested blood vessels and focal mature neuronal component and no immature elements seen, confirming dermoid cyst. Mesenteric cyst are rare intra-abdominal tumor found most commonly in ileum (60\%) next is ascending colon (40\%). However, if a mesenteric cyst locates within the pelvic cavity, as in this case, it may be misdiagnosed as an ovarian cyst.
\end{abstract}

Keywords: Mesenteric teratoma, Dermoid ovarian cyst, Abdominal tumor

\section{INTRODUCTION}

Mesenteric cysts are one of the very rare entities with incidence of 1 in $1,00,000$ to 1 in 2,50,000 admissions. ${ }^{1,2}$ Mesenteric dermoid cyst are even rarer. ${ }^{3}$ Dermoid cysts, which are also known as mature cystic teratoma's are the most common primary ovarian neoplasm accounting for $15-20 \%$ of total ovarian malignancy. ${ }^{4}$ These tumor originate from totipotent germ cells which have the ability to develop into the well differentiated tissues of any of the three germ lines. ${ }^{3,4}$ These cysts usually contain hair and sebaceous material and are lined by squamous epithelium. They are generally slow growing, rarely malignant $(1.7 \%)$ and have good prognosis. ${ }^{3,4}$ Here, we report a rare case of huge abdominal tumor which was initially misdiagnosed as an ovarian dermoid cyst but operative and histopathology revealed it to be a mesenteric dermoid cyst.

\section{CASE REPORT}

A 36 year old, multipara presented at gynaecology outpatient department (OPD) of Pt. J. N. M. Medical College, with complains of abdominal mass gradually increasing in size since 1 year and abdominal pain since 1 month. She had three vaginal deliveries and her menstrual cycles were regular with normal menstrual flow. Her bowel and bladder habits were normal. She had no significant past medical or surgical history. Physical examination revealed abdominal mass of $22 \times 20 \mathrm{~cm}$ occupying whole of the abdomen. The swelling was with 
different consistencies, firm towards right side and cystic towards left. The margins were smooth and had limited mobility from side to side. There was no tenderness on palpation. Per speculum examination was within normal limit. Per vaginal examination revealed uterus to be of normal size separately felt from the swelling. The swelling could be moved upwards, but not with cervical movements. All the fornices were occupied by this huge mass. The woman was subjected to ultrasound whole abdomen and pelvis which showed $14 \times 20 \times 21 \mathrm{~cm}$ heterogeneously hyperechoic abdomino-pelvic mass with few hypoechogenic areas and multiple calicfic foci noted within it.

CECT abdomen and pelvis (Figure 1) suggested a $23 \times 21 \times 14.4 \mathrm{~cm}$ abdomino-pelvic well defined, lobulated, heterogeneously enhancing soft tissue density mass lesion with areas of fat density with multiple areas of dense calcification, suggestive of teratoma, suggesting dermoid cyst.

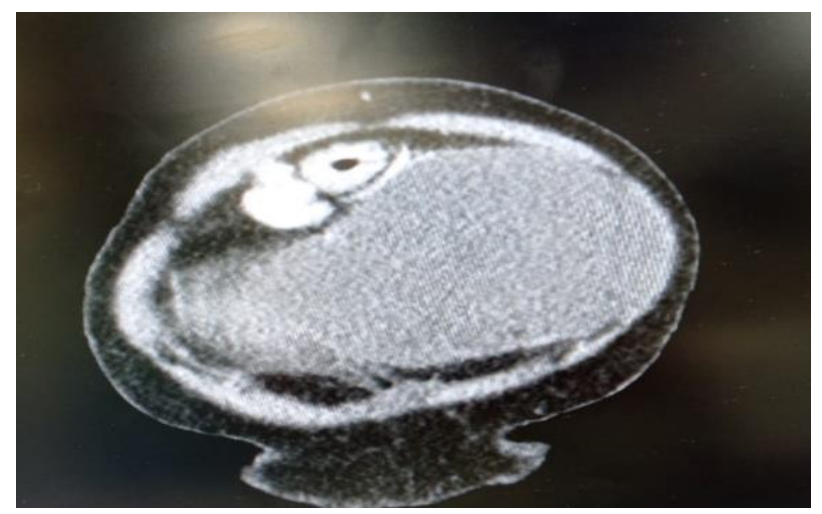

Figure 1: CECT abdomen and pelvis: A $23 \times 21 \times 14.4$ $\mathrm{cm}$ heterogeneous mass having fat density areas and dense calcification suggestive of teratoma.

Her ovarian tumor markers were assayed and found to be within normal limits. With the provisional diagnosis of ovarian teratoma, she was planned for exploratory laparotomy with vertical midline incision. On surgical exploration, a huge mass of $22 \times 20 \mathrm{~cm}$ was noted in the midline which was covered with omentum on all the sides (Figure 2). Posteriorly, it was adhered to small bowel from distal jejunum to distal ileum. Bilateral ovaries were found to be normal. Careful dissection from the omentum and complete resection of mass was performed. The mass was subjected to histopathological examination.

Gross findings suggested a $6.5 \mathrm{~kg}$ globular mass measuring $71 \mathrm{~cm}$ in circumference (Figure 3 ). Cut surface showed multiple teeth like structures at few places. Microscopic findings showed mature cartilage, osteoid formation, fibro-adipose connective tissue, focal lymphoid aggregates, few congested blood vessels along with focal mature neuronal component. No immature elements were seen. All these features were consistent with dermoid cyst.

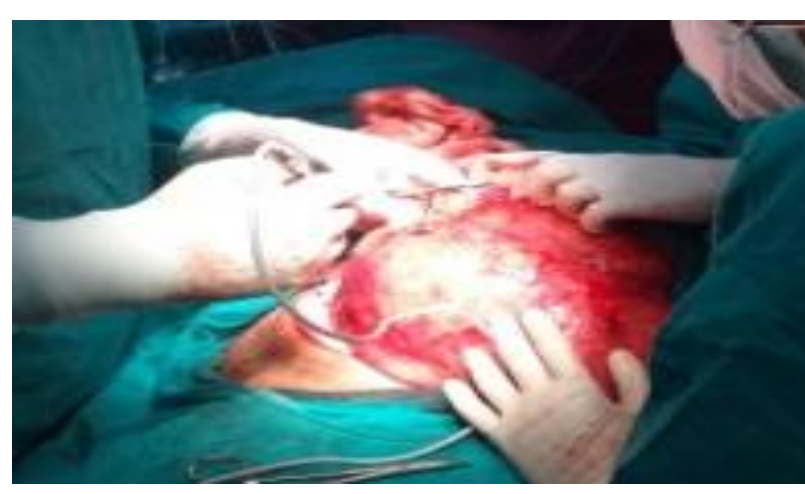

Figure 2: A mass of $22 \times 20 \mathrm{~cm}$ in the midline covered with omentum on all the sides.

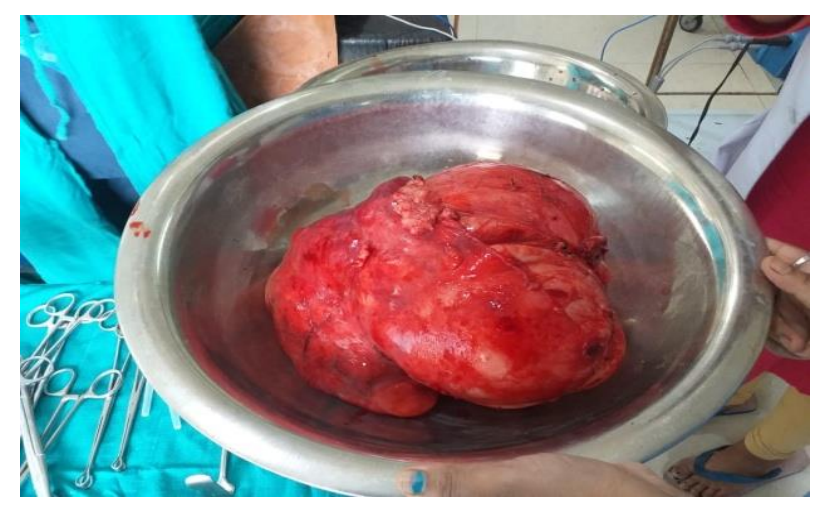

Figure 3: Gross finding showing a $6.5 \mathrm{~kg}$ globular mass measuring $71 \mathrm{~cm}$ in circumference.

\section{DISCUSSION}

Teratoma or dermoid cyst are germ cell tumors composed of multiple cell types which are derived from one or more of three germ layers. ${ }^{3}$ Usually, they occur in early age group. ${ }^{3,4}$ Dermoids can occur anywhere in pathway of ectodermal cell migration, especially in the midline, from cranium, mediastinum and retroperitoneum to sacrococcygeal regions. The most common location is sacrococcygeal (57\%) and in the gonads, that too in ovary. ${ }^{3}$ Dermoids rarely present as mesenteric cysts. ${ }^{3}$ This case needs to be reported as it is a mature teratoma which was originating from the mesentery and mature mesenteric teratoma in adulthood is extremely rare.

The teratomas are usually smaller than $10 \mathrm{~cm}$ with cystic spaces filled with sebaceous material containing matted hair, sometimes teeth, bone, etc. But, here in this case the size of the dermoid was unusually large, that is of $22 \mathrm{~cm}$.

Any abdominal mass which is freely mobile perpendicular to the attachment of mesentery is expected to be originating from mesentery itself. ${ }^{5}$ But, because of huge size, the mass which fills the abdominal cavity completely may not show the usual pattern of mobility, as in this case. Usually, these mesenteric masses are painless., Abdominal distension is the most common presentation and abdominal pain, if present, is because of the mass 
effect, leading to bowel obstruction or pressure symptoms over the bladder and sometimes hydro-ureteronephrosis. ${ }^{1,5}$

Various sonographic features suggestive of dermoid cyst, include echogenic calcification in a cystic mass, cyst with fat fluid level, hyperechogenic lines and dots. ${ }^{6,7}$ The site of origin in this case was difficult to diagnose by transabdominal or transvaginal sonography because of its huge size. The specific CT scan characteristics include a mass with well-defined margins, one or more cystic components with areas of calcification or fatty attenuation. ${ }^{1,6}$ Many a times, a solid protuberance is seen projecting into the cyst cavity (Rokitansky protuberance, dermoid plug). Calcifications are commonly seen in the solid component or in its wall. ${ }^{6,7}$

Complete surgical excision along with full histopathological examination of specimen is always recommended to rule out immature elements which may need chemotherapy in post-operative period. The incidence of malignancy in mesentery cyst is reported to be less than $3 \% .^{3}$ Dermoids may present with complications such as torsion $(15 \%)$, rupture, spillage, peritonitis, squamous cell carcinoma and recurrence. ${ }^{7}$

\section{CONCLUSION}

This rare case of mesenteric dermoid needs the attention of medical fraternity because of its unusual age of presentation, unusual site of origin and unusual size. The treatment of this rare entity is complete surgical excision followed by detailed surgical examination. It can be treated by laproscopy or laprotomy surgeries. Laproscopic approach is gaining acceptance but for large dermoid cysts, laprotomy is preferred to avoid spillage and peritonitis.
Funding: No funding sources Conflict of interest: None declared Ethical approval: Not required

\section{REFERENCES}

1. Pithawa AK, Bansal AS, Kochar SP. Mesenteric cyst: A rare intra-abdominal tumour. Med J Armed Forces India. 2014;70(1):79-82.

2. Kim SI, Kim YD, Jee BC, Lee HS. A case of mesenteric cyst confused with ovarianendometrioma. Korean J Obstet Gynecol. 2012;55(9):683-6.

3. Neeralagi CS, Surag KR, Kumar Y, Lakkanna S, Raj P. Mesenteric Teratoma in Elderly Female: A Rare Case Report. J Clin Diagn Res. 2017;11(1):1-2.

4. Hasanzadeh M, Tabare S, MIrzaean S. Ovarian dermoid cyst. Professional Med J Sep. 2010;17(3):512-5.

5. Kamat M, Barman S, Ray A, Shetye S, Sharma V, Sathyan J. Excision of intraabdominal mesenteric immature teratoma during COVID-19 pandemic. Int Surg J 2020;7:4221-4.

6. Kumar S, Kumar R, Nanjaraj CP, Joshi V. Cystic Teratoma of Mesentery: A Case Report and Review of Literature. J Evol Med Dent Sci. 2014;3(40):10183-7.

7. Deguchy Q, Fananapazir G, Corwin MT, Lamba R, Gerscovich EO, McGahan JP. Benign Rapidly Growing Ovarian Dermoid Cysts: A Case Series. J Diagnost Med Sonograph. 2017;33(1):71-4.

Cite this article as: Kishore $\mathrm{K}$, Lambodari $\mathrm{P}$, Verma K, Khan A, Singh N. A huge mesenteric teratoma in reproductive age woman: a case report. Int J Reprod Contracept Obstet Gynecol 2021;10:4590-2. 